\title{
Retraction Note: Assessment of the influence of whole body vibration on Cochlear function
}

Seyyed-Ali Moussavi-Najarkola ${ }^{1}$, Ali Khavanin ${ }^{1 *}$, Ramazan Mirzaei ${ }^{2}$, Mojdeh Salehnia $^{3}$ and Mehdi Akbari ${ }^{4}$

\section{Retraction Note}

The Editors-in-Chief are retracting this article [1] as it has already been published in In Vitro Cellular \& Developmental Biology - Animal [2]. The authors do not agree with this retraction.

\author{
Author details \\ ${ }^{1}$ Department of Occupational Health, School of Medical Sciences, Tarbiat \\ Modares University (TMU), Tehran, Iran. ${ }^{2}$ Department of Occupational Health, \\ Health promotion research center, Zahedan University of Medical Sciences \\ (ZUMS), Zahedan, Iran. ${ }^{3}$ Department of Anatomical Sciences, School of \\ Medical Sciences, Tarbiat Modares University (TMU), Tehran, Iran. \\ ${ }^{4}$ Department of Audiology, School of Rehabilitation, Iran University of \\ Medical Sciences (IUMS), Tehran, Iran.
}

Received: 12 June 2017 Accepted: 16 June 2017

Published online: 29 June 2017

\section{References}

1. Moussavi-Najarkola S, Khavanin A, Mirzaei R, Salehnia M, Akbari M. Assessment of the influence of whole body vibration on Cochlear function. Journal of Occupational Medicine and Toxicology. 2012;7:12.

2. Moussavi-Najarkola S, Khavanin A, Mirzaei R, Salehnia M, Akbari M. Effects of whole body vibration on outer hair cells' hearing response to distortion product otoacoustic emissions. In Vitro Cell Dev Biol Anim. 2012;48(5):276-83.

\footnotetext{
* Correspondence: khavanin@modares.ac.ir

${ }^{1}$ Department of Occupational Health, School of Medical Sciences, Tarbiat Modares University (TMU), Tehran, Iran
} 